\title{
Hammer Throwing parameters optimization model research based on flight dynamical differential equation
}

\author{
Jun Liu \\ Department of Physical Education, Dalian Polytechnic University, Dalian 116034, China
}

\begin{abstract}
With progress of times, sports techniques are also rapidly developing, in order to let Chinese hammer throwers more quickly improve themselves levels, the paper according to kinematic equation and geometrical analysis, it gets throwing distance main influence factors, and provides athletes themselves required bearing acting force equation when throwing hammer. In case considering air resistance to throwing distance and heights influences, establish hammer flight dynamical equation, and solve best release angle. Research shows when athlete final release speed arrives at, he suffered acting force is between, and the higher athlete final release speed is, the better performance would be, athletes can make targeted training combining with the paper data.
\end{abstract}

\section{Introduction}

Athletics was listed into game events in Athens first ancient Olympic Games in 776 B.C. In the earliest athletics game, only short-distance run such one item, till the 10th Olympic Games it listed into javelin throw, discuss throw and long jump as well as other game events, and hammer hasn't been listed into field events until the 2nd Olympic Games in 1900, is a kind of later development field event. The initial hammer throwing rule is throwing hammer in a circle with $2.5 \mathrm{~m}$ diameter, $90^{\circ}$ range area in front of circle is effective ace area, while later changed into $34.92^{\circ}$. At the beginning, hammer throwing mostly uses brute force, the performance is not good, but with progress of times, hammer throwing technique has been also gradually perfected, subsequently it developed into 4 rounds throwing technique, which largely speeded up hammer release speed, let hammer performance have larger breakthrough, present world record has already been $86.74 \mathrm{~m}$. For hammer development in China, it appeared in Chinese first sports meeting in 1910 as the earliest, at that time weight of ball is 12 pound, but performance is $32 \mathrm{~m}$. With new China founded, national liberation achieved, the records in 1957 and 1963 respectively successive arrived at $50.68 \mathrm{~m}$ and $62.33 \mathrm{~m}$, which just had 7.47 difference with current world record. After reform and opening, Chinese comprehensive national strength is constantly increasing [1]; the position in sports field gets more and more high. In 1998, Chinese woman athlete $\mathrm{Gu}$ Yuan threw 70m excellent performance, she won Chinese history first woman hammer gold medal and become the first Asian woman. In 2002, Gu Yuan broke through champion record with $71.10 \mathrm{~m}$ performance, subsequently she broke through total 14 times Asian women hammer records, which built solid foundations for Chinese women hammer leaps [2-4].

To further improve Chinese hammer throwing technique, the paper gradually analyzes hammer release speed and release angle influences on hammer throwing performance, finally it gets best hammer throwing angle. Athlete can combine with the paper achieved results to take corresponding training so as to improve performance.

\section{Hammer throwing biomechanical analysis}

Hammer court is a circle with $2.5 \mathrm{~m}$ diameter installed stop board, with $U$ cage fixed on surrounding of court. Cage is 7 pieces of $2.74 \mathrm{~m}$ backstop that composed of $5 \mathrm{~m}$ height, cage opening width is set as $6 \mathrm{~m}$ which is $3.5 \mathrm{~m}$ far from the front of throwing court circle center. Hammer is iron sphere, is respective composed of sphere, chain and handle. And tail chain is made of high resilience, not easy to break steel wire, handle should be hard enough without any hinge joints, it has single loop and double loop two structures. Hammer standard weight for men is $7.26 \mathrm{~kg}$, for women is $4 \mathrm{~kg}$, the maximum diameters are respectively $13 \mathrm{~cm}$ and $11 \mathrm{~cm}$.

Hammer throwing divides into before releasing and after releasing two parts, before releasing athletes let hammer get rotational speed and make it speed up by themselves rotating, when releasing, they throw hammer along circular tangential direction with force. And after releasing, hammer makes parabola movement only affected by gravity, and then final performance

a Corresponding author: JunLiu@163.com 
merits are only related to speed, angle and height when releasing. Therefore, to get ideal performance, athletes should find out best throwing height and angle.
Hammer's distance from releasing to landing divides into two parts: before releasing distance and after releasing distance, the two influences factors are as Figure 1 shows.

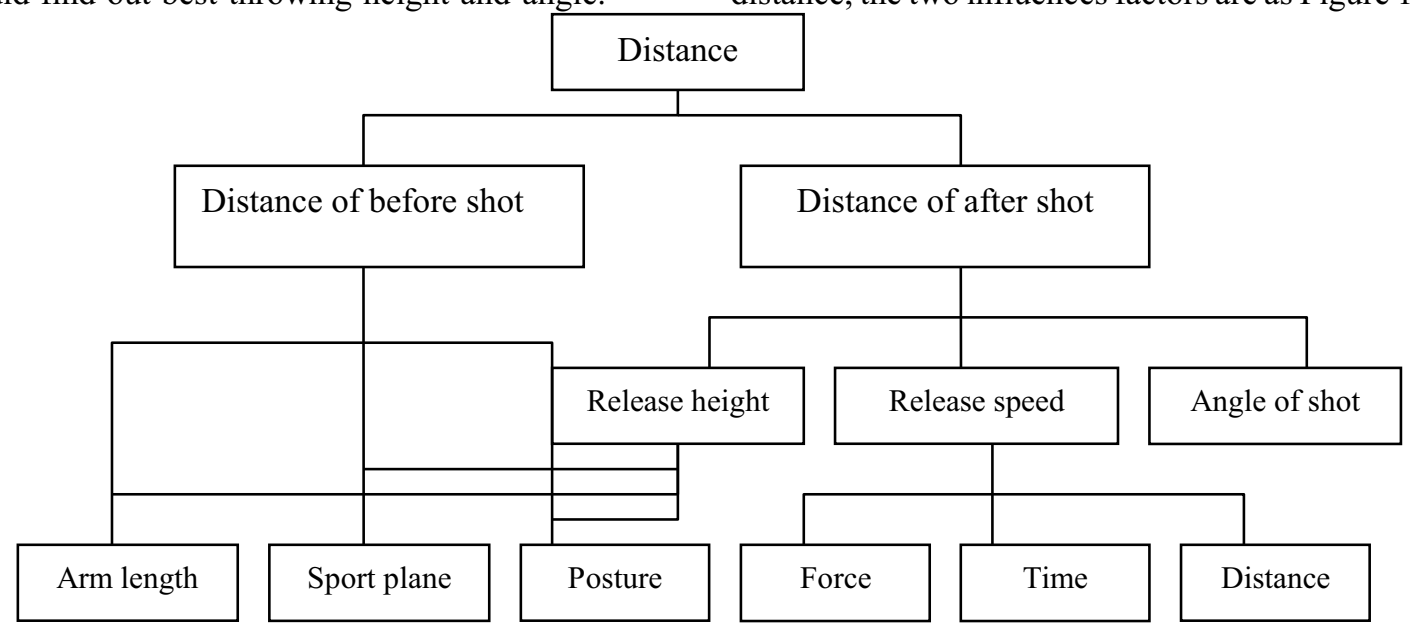

Figure 1. Distance influence factors analysis diagram

Hammer only makes parabola movement under gravity influence after releasing; this paper divides it into two direction that are horizontal direction and vertical direction. Horizontal direction is constant straight line movement, vertical direction is vertical up cast movement, and the formula is as following: $\left\{\begin{array}{l}x=v_{0 x} \cdot t=v_{0} \cos \theta \cdot t \\ y=v_{0 y} \cdot t-\frac{1}{2} g t^{2}=v_{0} \sin \theta \cdot t-\frac{1}{2} g t^{2}\end{array}\right.$

\subsection{Final release speed analysis.}

The paper first analyzes final release speed to final performance influence in case that angle and height fixed. Fixed parameters: release angle is $43^{\circ}$, release height is $1.6 \mathrm{~m}$, the result is as Table 1 .

From above Table 1, it is clear that release speed effects on throwing performance is very obvious. When speed is $14 \mathrm{~m} / \mathrm{s}$, throwing distance is only around $25 \mathrm{~m}$, and normal athletes final release speed is between $26 \sim 30 \mathrm{~m} / \mathrm{s}$, when release speed is $26 \mathrm{~m} / \mathrm{s}$, they can throw around $70 \mathrm{~m}$, and when final release speed is $27 \mathrm{~m} / \mathrm{s}, 28 \mathrm{~m} / \mathrm{s}$, optimal performance can arrive at $80 \mathrm{~m}$ even $90 \mathrm{~m}$. Therefore improve final release speed can remarkable improve athlete throwing performance.
By $y$, it can solve $t$ equation and input it into above formula, it gets throwing distance computational formula:

$$
x=\frac{v_{0}^{2} \sin \theta \cos \theta+v_{0} \cos \theta\left(v_{0}^{2} \sin ^{2} \theta+2 g h\right)^{1 / 2}}{g}
$$

From throwing performance computational formula, it is clear that hammer throwing distance main influence factors are release angle, release height and final release speed, and the final release speed is the first influence element.

Hammer thrower in throwing hammer moment, he should first rotates several circles let hammer speed up, so hammer before releasing movement trajectory should be Figure 2 showed circular movement, and then it will throw out along tangent line when final releasing. At this time ball chain acting on ball force $F_{1}$ according to D'Alembert principle, sizes should be equal to ball suffered normal inertial force that athlete suffered acting force size is also equal to $F_{1}$ that is:

$$
F_{1}=m \frac{v_{0}^{2}}{r}
$$

In above formula, $m$ is hammer mass, $r$ is round radius, $v_{0}$ is hammer final release speed.

Table 1. Final release speed to performance influence.

\begin{tabular}{|c|c|c|c|c|c|c|c|c|c|c|c|}
\hline Speed(m/s) & 14 & 20 & 22 & 23 & 24 & 25 & 26 & 27 & 28 & 29 & 30 \\
\hline Performance $(\mathrm{m})$ & 25.45 & 42.57 & 50.83 & 55.46 & 60.03 & 65.12 & 70.24 & 82.31 & 87.88 & 93.4 & 97.5 \\
\hline
\end{tabular}

Table 3: Different release angles to distance influences.

\begin{tabular}{|c|c|c|c|c|c|c|c|c|c|c|c|}
\hline Angle & 30 & 35 & 38 & 40 & 43 & 45 & 48 & 50 & 55 & 58 & 60 \\
\hline Distance(m) & 66.92 & 71.98 & 74.05 & 75.00 & 75.78 & 75.86 & 78.63 & 74.89 & 70.68 & 68.31 & 65.42 \\
\hline
\end{tabular}




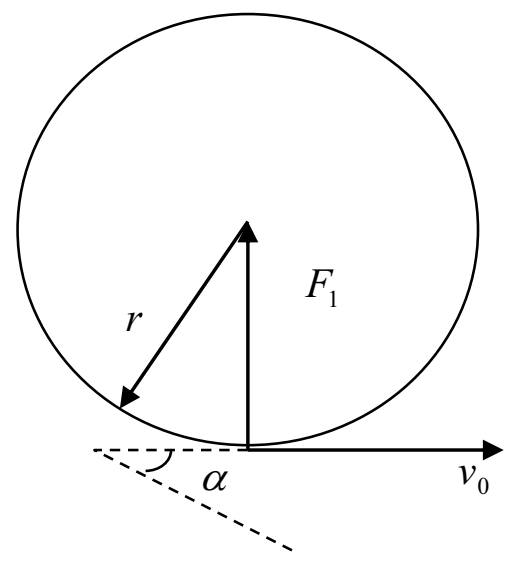

Figure 2. Hammer releasing schematic diagram.

According to above formula $F_{1}=m \frac{v_{0}{ }^{2}}{r}$, set hammer mass as $11 \mathrm{~kg}$, length as $1.22 \mathrm{~m}$, it respectively gets force $F_{1}$ as well as final release speed and radius $r$ change rules refer to Table 2 .

Table 2. Force $F_{1}$ final release speed and radius relations

\begin{tabular}{|c|c|c|}
\hline \multirow{2}{*}{ Final release speed $v_{0}(\mathrm{~m} / \mathrm{s})$} & \multicolumn{2}{|c|}{ Acting force $F_{1}(K N)$} \\
\cline { 2 - 3 } & $r=2.07 \mathrm{~m}$ & $r=2.12 \mathrm{~m}$ \\
\hline 26 & 2.431 & 2.387 \\
\hline 27 & 2.556 & 2.454 \\
\hline 28 & 2.749 & 2.684 \\
\hline 29 & 2.948 & 2.879 \\
\hline 30 & 3.155 & 3.081 \\
\hline 31 & 3.369 & 3.198 \\
\hline
\end{tabular}

\subsection{Release angle and height analysis.}

When ignoring air resistance, hammer throwing can be regarded as standard oblique projectile movement. When release height and release speed are fixed, different release angles will let athletes throwing performance have obvious differences, Figure 3 is different release angles formed parabola trajectory [5].

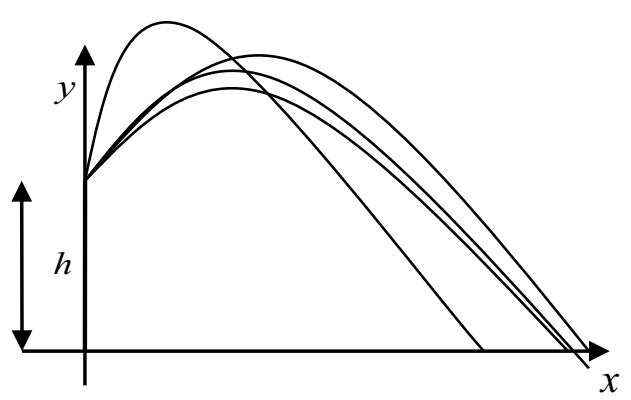

Figure 3. Release angle and distance relations

Figure 3 shows release angle can arrive at best distance only in certain range. In case no air resistance influences, parabola movement, when release angle is $45^{\circ}$, parabola span is the largest. Table 3 is release angle and distance relations.

In practical situation, hammer after releasing, except for gravity influence, it will also suffer air streaming resistance.
In order to simplify, now regard hammer as a particle, according to Newton's motion law, and hammer after releasing movement form is as Figure 4 show.

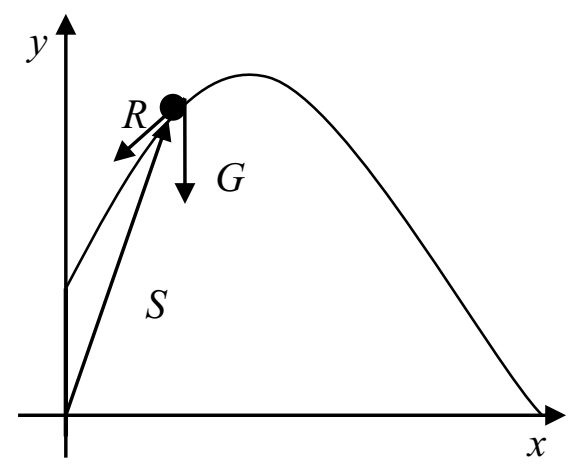

Figure 4. Hammer air movement schematic diagram.

In Figure $4, S$ is radius vector, $R$ is air resistance. Therefore hammer movement can use differential equation to express as:

$$
m \frac{d^{2} s}{d t^{2}}=G+R
$$

And according to fluid mechanics, it is clear that when hammer flies in the air, it will produce tail flow, further let air form into streaming resistance to it. Streaming resistance is in direct proportion to air dynamic pressure, expression is:

$$
R=-c A \frac{\rho V^{2}}{2}
$$

Among them, $c$ is resistance coefficient, $A=\frac{\pi d^{2}}{4}, \rho$ is air density, $v$ is hammer speed, $d$ is hammer diameter. Input formula (2) into formula (1), it can get:

$$
\left\{\begin{array}{c}
m \frac{d^{2} x}{d t^{2}}=-\frac{c A \rho}{2}\left(v_{x}^{2}+v_{y}^{2}\right)^{\frac{1}{2}} v_{x} \\
m \frac{d^{2} y}{d t^{2}}=-m g-\frac{c A \rho}{2}\left(v_{x}^{2}+v_{y}^{2}\right)^{\frac{1}{2}} v_{y}
\end{array}\right.
$$

When solving above equations, let $z_{1}=x, z_{2}=\frac{d x}{d t}, z_{3}=y, z_{4}=\frac{d y}{d t}$.

In this way simplify above formula into four pieces of one orders differential equation:

$$
\left\{\begin{aligned}
\frac{d z_{1}}{d t} & =z_{2} \\
\frac{d z_{2}}{d t} & =-\frac{c A \rho}{2 m}\left(z_{2}^{2}+z_{4}^{2}\right)^{\frac{1}{2}} z_{2} \\
\frac{d z_{3}}{d t} & =z_{4} \\
\frac{d z_{4}}{d t}= & =g-\frac{c A \rho}{2 m}\left(z_{2}^{2}+z_{4}^{2}\right)^{\frac{1}{2}} z_{4}
\end{aligned}\right.
$$


Adopt Runge-kutta numerical integration to make solution on above formula, and get hammer flight distance and height as well as release angle, release height, release speed and air resistance coefficient relations, which can respectively refer to Tables 4-7.

Table 4. Release angle and distance, height relations.

\begin{tabular}{|c|c|c|}
\hline $\begin{array}{c}\text { Release } \\
\text { angle } \alpha\left(^{\circ}\right)\end{array}$ & $\begin{array}{c}\text { Distance } \\
(m)\end{array}$ & $\begin{array}{c}\text { Maximum } \\
\text { height }(m)\end{array}$ \\
\hline 40 & 87.03 & 19.85 \\
\hline 42 & 87.67 & 21.35 \\
\hline 44 & 87.91 & 22.87 \\
\hline 45 & 87.88 & 23.62 \\
\hline 48 & 87.64 & 22.11 \\
\hline 50 & 87.08 & 20.60 \\
\hline
\end{tabular}

Note: release speed $29 \mathrm{~m} / \mathrm{s}$, release height $h=1.75 \mathrm{~m}$, resistance $c=0.47$

Table 5. Release height and distance, height relations.

\begin{tabular}{|c|c|c|}
\hline $\begin{array}{c}\text { Release } \\
\text { height }(h / m)\end{array}$ & $\begin{array}{c}\text { Distance } \\
(m)\end{array}$ & $\begin{array}{c}\text { Maximum } \\
\text { height }(m)\end{array}$ \\
\hline 1.65 & 87.53 & 21.22 \\
\hline 1.70 & 87.59 & 21.27 \\
\hline 1.75 & 87.64 & 21.32 \\
\hline 1.80 & 87.69 & 21.37 \\
\hline 1.85 & 87.74 & 21.42 \\
\hline 1.90 & 87.79 & 21.47 \\
\hline
\end{tabular}

Note: release angle $42^{\circ}$, final release speed $29 \mathrm{~m} / \mathrm{s}$, resistance coefficient $c=0.47$

Table 6. Final release speed and distance, height relations.

\begin{tabular}{|c|c|c|}
\hline $\begin{array}{c}\text { Final release speed } \\
v_{0}(m / s)\end{array}$ & $\begin{array}{c}\text { Distance } \\
(m)\end{array}$ & $\begin{array}{c}\text { Maximum } \\
\text { height }\end{array}$ \\
\hline 26 & 73.38 & 17.31 \\
\hline 27 & 75.42 & 18.65 \\
\hline 28 & 79.39 & 19.44 \\
\hline 29 & 84.87 & 20.71 \\
\hline 30 & 90.52 & 22.01 \\
\hline 31 & 94.0 & 23.45 \\
\hline
\end{tabular}

Note: release angle $42^{\circ}$, release height $1.75 \mathrm{~m}$, resistance coefficient $c=0.47$

From Table 4,Table 5, Table 6 and Table 7, it is clear that release angle, release height, final release speed and air resistance coefficient have different levels influences on athletes final performance, final release speed to performance influence is most remarkable, flight distance is also remarkable improving with final release speed increasing. And release height and air resistance coefficient to athletes' final performance influences are not remarkable. In practical situation, athletes positioned environment is basically consistent, average height is basically the same, so best choice for improving performance is strengthen final release speed training and release angle control.

Table 7. Resistance coefficient and distance, height relations.

\begin{tabular}{|c|c|c|}
\hline Resistance coefficient $c$ & $\begin{array}{c}\text { Distance } \\
(m)\end{array}$ & $\begin{array}{c}\text { Maximum } \\
\text { height }(m)\end{array}$ \\
\hline 0.41 & 87.99 & 21.39 \\
\hline 0.43 & 87.88 & 21.38 \\
\hline 0.45 & 87.78 & 21.37 \\
\hline 0.47 & 87.67 & 21.35 \\
\hline 0.49 & 87.56 & 21.34 \\
\hline 0.51 & 87.46 & 21.33 \\
\hline
\end{tabular}

Note: release angle $42^{\circ}$, final release speed $29 \mathrm{~m} / \mathrm{s}$, release height $h=1.75 \mathrm{~m}$

\section{Conclusion}

This paper by mutual combining kinematic equations and geometrical analysis, it gets throwing distance main influence factors, and it provides athletes' themselves required bearing acting force equations when throwing hammer. And consider air resistance to throwing distance and height influences, and establishes hammer dynamical differential equation when flying in the air, it solves best release angle. Finally, it gets best release angle is $44^{\circ}$. When athlete final release speed arrives at $26 \sim 30 \mathrm{~m} / \mathrm{s}$, he suffered acting force is between $2 K N \sim 3 K N$, and the higher athlete final release speed is, the better performance would be. In professional game, athletes positioned environment is basically consistent, average height is basically the same, therefore release height and air resistance to performance influences are not very big, it can ignore.

\section{References}

1. B. Peng, B. Xia and Z. L. Liu, Advanced Materials Research, 213, 107-110 (2011).

2. Y. Geng and G. L. Song, Journal of Shandong Physical Education Institute, 20, 56-57 (2004).

3. J. Ye, Journal of Chengdu Physical Education Institute, 38, 79-82 (2012).

4. J. M. Chen, Journal of Beijing Sport University, 28, 703-705 (2005).

5. G. Ruiz-Martínez, I. Mariño-Tapia and E. G. M. Baldwin et al, Journal of Coastal Research, 32, 651-669(2016). 